\title{
Isolated Tuberculosis of Gallbladder: A Case Report
}

\author{
Mohammad Ismail Hossain ${ }^{* 1}$ \\ A K M Shahabuddin Khan ${ }^{2}$ \\ ${ }^{1}$ Department of Pathology \\ Chittagong Medical College, Chittagong, Bangladesh. \\ ${ }^{2}$ Department of Pathology \\ Comilla Medical College, Comilla, Bangladesh
}

\begin{abstract}
Tuberculosis of the gall bladder, a rarity in itself, is always found associated with gallstones or cystic duct obstruction. It presents as a part of systemic miliary tuberculosis, abdominal tuberculosis, isolated gallbladder tuberculosis and as acalculus cholecystitis in anergic patients. There are no pathognomonic signs; the diagnosis depends on suspicion of tuberculosis, preoperative findings and histological examination. This is case of a 60 year old diabetic smoker male; who presented with features of calculouscholecystitis, but after cholecystectomy, on histopathology was proved to be tuberculous gall bladder. The present case of tuberculosis of the gall bladder is being reported for its extreme rarity as it was associated gallstones and thick walled gallbladder mimicking neoplasm.
\end{abstract}

Key words: Gallbladder; Tuberculosis; Calculouscholecystitis.

\section{INTRODUCTION}

Although involvement of the liver is common, tuberculosis only rarely infects the biliary system ${ }^{1}$. The gall bladder is an unlikely gastrointestinalorgan to develop primary tuberculosis ${ }^{2}$. Historically, isolated tuberculosis of gall bladder was reportedfor the first time in 1870 by Gaucher ${ }^{3}$. Gallbladder Tuberculosis (GT) is a rare disease and only alimited number of patients have beenreported ${ }^{4}$. However, hepatobiliary tuberculosis israre, seen in aproximately $1 \%$ of all abdominal cases ${ }^{5}$. Pre-operative diagnosis ofgall bladder tuberculosis is difficult and post-operative persistence of symptoms due to tuberculosis are sometimes misdiagnosed as the "post-cholecystectomy syndrome". Hepatobiliary TB is more common in males with a maleto female ratio of 2:1 and there is no specific age group butaccording to one study the majority of patients fall within theage range of 11-50 years ${ }^{7}$. A correct preoperative diagnosis of GT is unusual, and it is frequently confused with variousgallbladder diseases ${ }^{8}$. Rarity of tubercular involvement of the gallbladder has been attributed to the high alkalinity ofbile and bile acid inhibiting the growth of tuberclebacillus 9 . Here, we report a case of Gallbladder tuberculosis mimicking malignant neoplasm, clinically and sonographically.

\section{CASE REPORT}

A 60 years old diabetic smoker male presented with the complaints of dyspepsia, anorexia, right upper abdominal pain on \& off for last 6 months which relieved by antispasmodics, associated with low grade fever, occasional vomiting, specially after meal. The examination of abdomen revealed slight tenderness in right hypochondrium but no palpable lump. There was no splenomegaly, lymphadenopathy, jaundice or ascitis. Haematological examination reveals $\mathrm{Hb}$ $10 \mathrm{gm} / \mathrm{dl}$, TLC $12000 / \mathrm{cmm}$ with lymphocytic leucocytosis, ESR $95 \mathrm{~mm}$ in $1^{\text {st }}$ hour. Blood sugar, urea, creatinine, liver function tests were normal and stool for OBT negative. Ultrasonogram of abdomen showed thickened gallbladder [mimicking neoplasm] with stone. CXR [P/A view] was normal and sputum for AFB was negative.

In view of the symptomatic cholelithiasis, patient was posted for subcostal laparotomy. Intraoperative gallbladder was thickened and fibrotic, with dense adhesionto surrounding liver and duodenum. An exhaustive examination of the abdominal cavity revealed no ascitis or evidence of tubercles or neoplastic seedling in the peritoneal cavity. 


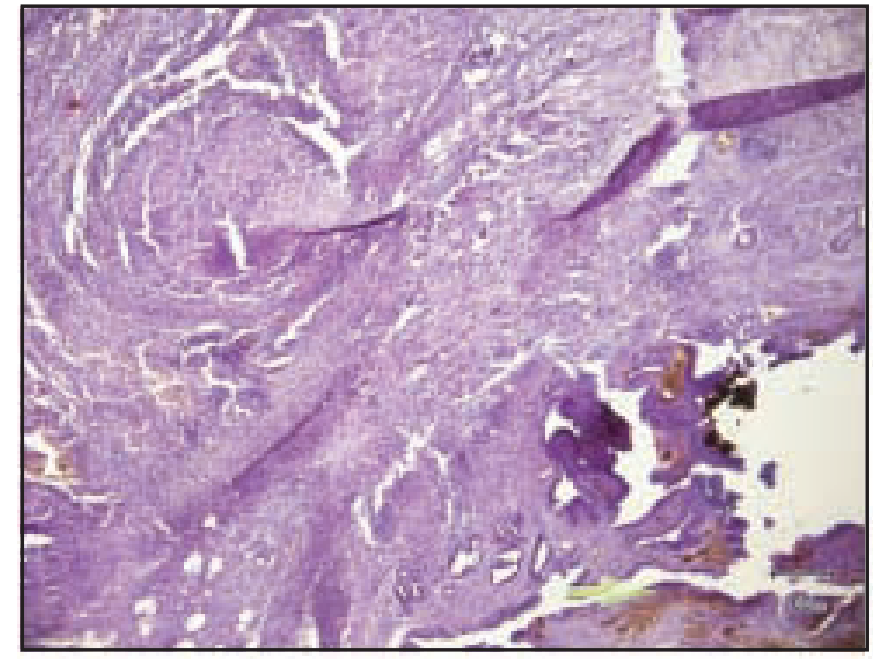

Figure 1: Gallbladder wall with granuloma [Right] [40X]

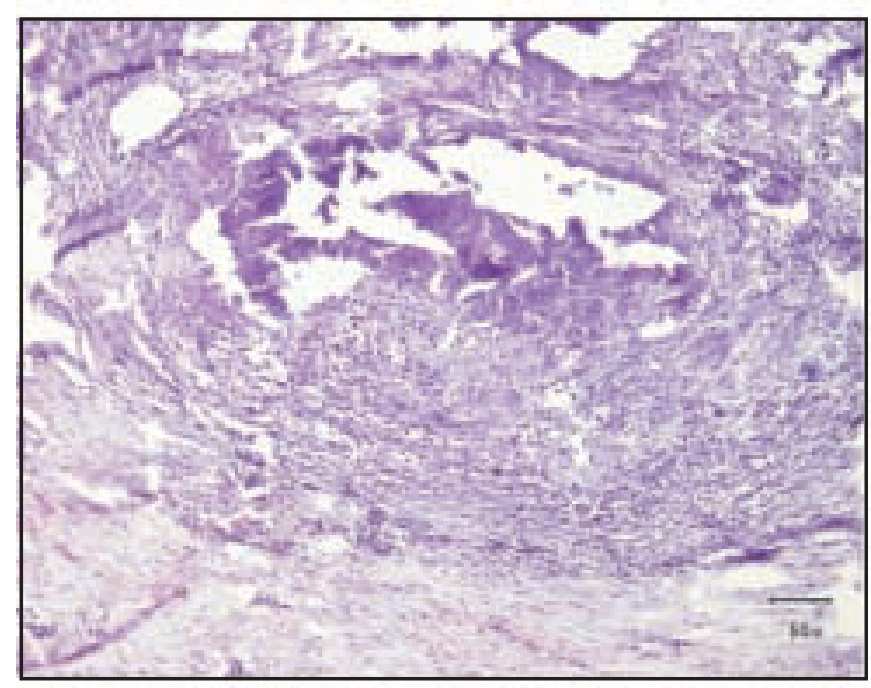

Figure 3 : Caseous necrosis [400X magnification]

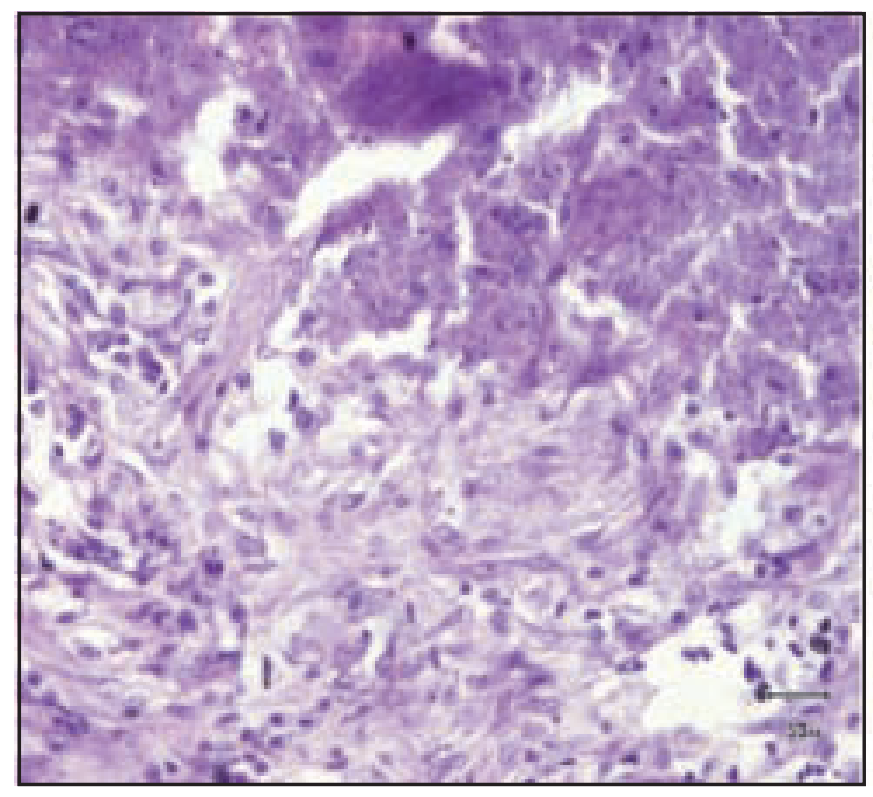

Figure 5 : Langhans type giant cells[400X magnification] [Haematoxillin\& Eosin stain]

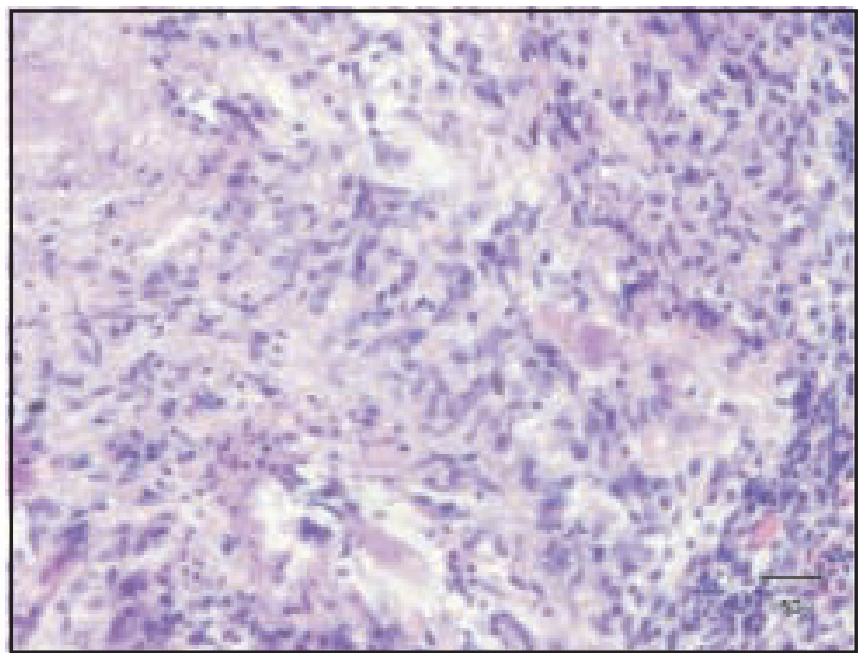

Figure 2: Well formed granuloma [100X magnification]

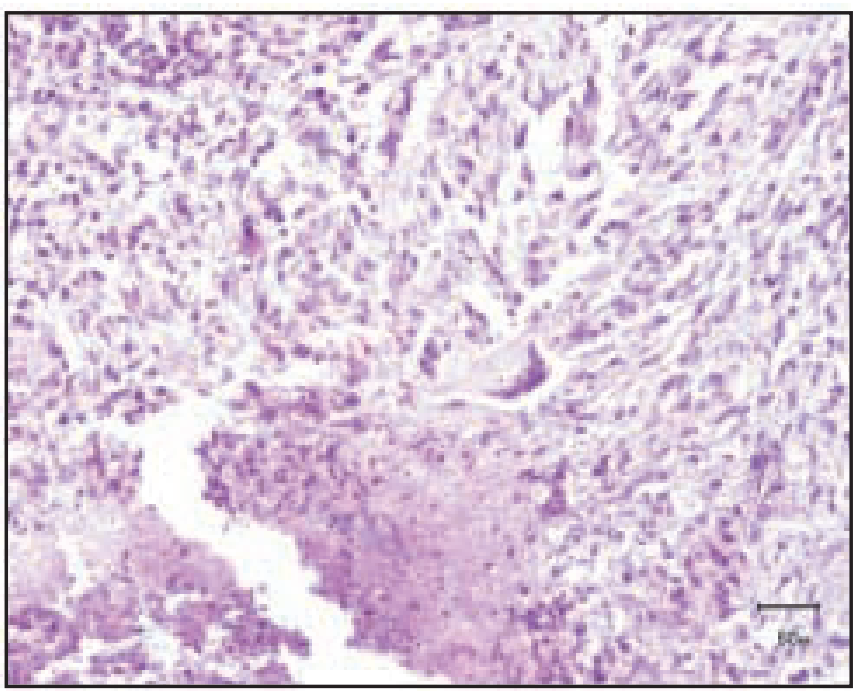

Figure 4 : Epithelioid cell cluster [400X magnification]

Cholecystectomy was performed, which required a difficult dissection due to dense adhesion. The excised specimen was sent for histopathological examination. The diseased gallbladder was $4 \times 2.5 \times 2 \mathrm{~cm}$ and there was a large stone. Histopathological examination revealed multiple caseatinggranuloma composed of caseation necrosis, aggregates of epithelioid cells and occasional Langhans type giant cells suggestive of tuberculosis of gallbladder. The postoperative course was uneventful, discharged on $4^{\text {th }}$ postoperative day, antitubercular drug therapy was started and eventually patient made a good recovery.

\section{DISCUSSION}

Despite a high prevalence of tuberculosis of thegastrointestinal tract, tubercular involvement of the gallbladder is very rare. Rarity of tubercular involvement of the gallbladder has been attributed to the high alkalinity ofbile and bile acid inhibiting the growth of tuberclebacillus. It has been suggested that cystic ductobstruction leads to the disappearance of bile acid fromthe gall bladder and therefore to a lowered resistanceagainst this infection. Previous damage to the gallbladder lining epithelium 
due to gall stones seems to be a prerequisitefor the development of tuberculouscholecystitis asalmost all reported cases have coexistent gallstones ${ }^{9}$. Isolated gall bladder tuberculosis generally occurs in womenover 30 years old. The usual presentation is vague right upperabdominal pain, weight loss, fever, nausea, vomiting \&diarrhea. Very rarely, there is a palpable abdominal lump. ${ }^{3}$ Our patient was 60 years old diabetic, nonsmoker male withchronic right upper abdominal pain, consistent with usualpresentation of other cases.

According to Sir BOA Moynihan, a "gall stone is a tomb-stone erected to the memory of theorganism within it". Infecting organisms reach gall bladder via blood stream or lymphatics from a focus nearby.

So, mycobacteria can also be a cause of cholelithiasis and/or cholecystitis, particularly when tuberculosis is disseminated to the peritoneum and lymphnodes in the vicinity ${ }^{6}$. The gallbladder is infected by mycobacteriumtuberculosis as a part of miliary tuberculosis, abdominal tuberculosis or through the enterohepaticroute. Four distinct clinical varieties ofgallbladder tuberculosis are recognised: (1) As a component of miliary tuberculosis inchildren and in adults, (2) As a component ofdisseminated abdominal tuberculosis, (3) Isolated gallbladder tuberculosis withoutovert tubercular foci elsewhere in the body and (4) Involvement of gallbladder in anergic statesdue to uraemia, cancer or AIDS $^{2}$. About $70 \%$ of GT cases are accompanied bygallstones.
The route of infection may be peritoneal, hematogenous or lympathic. The differential diagnosis of GT includes acute and chronic cholecystitis, polypoid lesions and gallbladder carcinoma. The presence of a mass that fills the gallbladder associated with cholelitiasis is indistinguishable from carcinoma of the gallbladder. Moreover, both GT and carcinoma can give rise to regional lymph nodes. The presence of liver metastasis or liver infiltration suggests the presence of a gallbladder carcinoma. On the other hand, lung lesions or mesenteric thickening is frequent in patients with tubercular infection ${ }^{8}$. As tuberculouscholecystitis is difficult to diagnose, all resected cholecystectomy specimens should be sent for histopathological examination for evidence of tuberculosis ${ }^{6}$. The problem of the diagnosis of tubercular involvement of the gall bladder is obvious as all the signs, symptoms and investigation are non-specific. Ironically, postoperative histopathological confirmation becomes the greatest tragedy of diagnosis because a condition that is curable medically has to follow surgery unavoidably ${ }^{9}$.

\section{CONCLUSION}

This case highlights the need to be aware of GIT and hepatobilliarytuberculous disease in endemic areas of tuberculosis, and in patients with chronic GIT symptoms.

\section{DISCLOSURE}

All the authors declared no competing interest.

\section{REFERENCES}

1. Vilaichone R-K, Mahachai V. Tuberculousacalculouscholecystitis: a case report. J Infect Dis antimicrob Agents. 2005; 22:127-131.

2. Kumar K, Ayub M, Kumar M, Keswani NK, Shukla HS. Tuberculosis of gallbladder.HPB Surgery. 2000; 11:401-404.

3. Bendre M, Rane N, Narwade N. Isolated tuberculosis of gallbladder: A case report.Indian Journal of Applied Research. 2014; 4(4): $439-440$.

4. Ali AE, Shibly ETME, Sheikh HE. Tuberculous gallbladder mass in a 7 -year-old child with chronic right upper quadrant pain Sudan Med J. 2011; 47(1): 32-35.

5. de Melo VA, de Melo GV, Silva RL, Piva S, Almeida MLR. Tuberculosis of the cystic duct lymphnode.The Brazilian Journal of Infectious Diseases. 2004; 8(1): 112-114.

6. Mukherjee S, Ghosh AK, Bhattacharya U. Tuberculosis of gallbladder-problem of diagnosis. Ind J. Tub.2001; 48: 151-152.

7. Chaudhary P. Hepatobiliary tuberculosis. Annals of gastroenterology. 2014; 27: 1-5.

8. Ramia JM, Muffak K, Fernandez A, Villar J, Garrote D, Ferron JA. Gallbladder tuberculosis: False-positive PET diagnosis of gallbladder cancer. World J Gastroenterol. 2006; 12(40): 6559-6560.

9. Tanwani R, Sharma D, Chandrkar SK. Tuberculosis of gall bladder without associatedgall stones or cystic duct obstruction. Indian J Surgery. 2005; 67:45-46 